\title{
Effect of Tool Kinematics on Tube Flanging by Extrusion with a Moving Sleeve
}

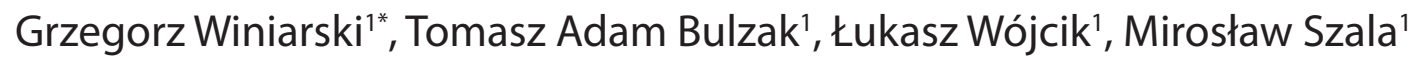 \\ ${ }^{1}$ Faculty of Mechanical Engineering, Lublin University of Technology, ul. Nadbystrzycka 36, 20-618 Lublin, \\ Poland \\ * Corresponding author's e-mail: g.winiarski@pollub.pl
}

\begin{abstract}
This paper presents the results of a numerical investigation into tube flanging by extrusion with a moving sleeve. Two cases of the extrusion process are investigated, each described with a different tool kinematics. Effects of flange diameter, gap height and tool motion on the extrusion process are examined. The numerical analysis is performed on $42 \mathrm{CrMo} 4$ steel tubes deformed at ambient temperature. Obtained numerical results are then used to determine metal flow patterns and examine force parameters in the extrusion process, as well as to determine a technological window for the investigated method.
\end{abstract}

Keywords: extrusion with a moving sleeve, $42 \mathrm{CrMo} 4$ steel, hollow parts, flange formation.

\section{INTRODUCTION}

Stepped shafts have many applications in engineering. They are used, among others, in the machine building, aircraft and mining industry as components for engine subassemblies, mechanical gears or power transmission systems. Stepped shafts can be produced by a number of different techniques, including metal forming processes for axisymmetric parts such as cross wedge rolling, upsetting, orbital forging, compression, flanging and radial extrusion.

Cross wedge rolling (CWR) can be used to produce stepped shafts, both hollow [1] and solid $[2,3]$. In this process the workpiece is deformed by tools in the form of plates or rolls with shaping wedges on their surface. Depending on the tool design and kinematics, several variations of this process can be distinguished, depending on the workpiece motion. The workpiece is rotated about its axis and - additionally - it either performs translational motion in the same direction as the tools or rotates about the rotation axis of the tools. Apart from the differences in kinematics, the process can also vary depending on the metal flow pattern (CWR by diameter reduction, CWR with upsetting (reverse) or CWR by parallel method). Similarly to cross wedge rolling, upsetting is used to produce stepped shafts, among others. A key parameter in the upsetting of bars is the limit upsetting ratio above which the bar end undergoes buckling, whereas in the upsetting of tube flanges [4] this fold defect may occur on the tube wall. This failure mode can be prevented e.g. by the application of multi-step upsetting [5]. The flange formed by multi-step upsetting is higher and has a bigger diameter than that produced by single-step upsetting. Similarly to upsetting, orbital forging is suitable for deforming bar sections [6, 7] or tubes [8]. The fundamental difference lies in the fact that the momentary contact surface between the workpiece and the tools is several times smaller than that in upsetting, as a result of which the forming force can decrease by several times. In contrast to orbital forging and upsetting, the compression technique consists in reducing the cross dimensions of a finished part. Two variations of this process can be distinguished, depending on the tool and billet kinematics. In the first variation 
of the process, the tool moves straight along the symmetry axis of the fixed billet $[9,10]$, while in the other - the tools (rollers) are rotated about their symmetry axis and moved toward the axis of rotation of the workpiece[11, 12]. Flanging is similar to the first of the above-mentioned variations of the compression process, and it consists in forming flanges inside [13] or outside tubular specimens $[14,15]$. This process can also be used in the production of energy-absorbing structures [16]. Radial extrusion is suitable for forming parts with lateral protrusions or flanges from bars $[17,18]$ or tubes $[19,20]$. A serious failure mode observed in this process is radial fracture of the flange caused by circumferential tensile stresses.

A review of metal forming methods for stepped shafts has revealed that there are many techniques for producing these parts. Nevertheless, attempts are made to modify these methods in order to extend their application range or to develop new techniques. In light of the above, it is considered justified to investigate a new process of extrusion with a moving sleeve [21, 22]. The objective of this study is to determine the effect of flange diameter, gap height and tool kinematics on the process of tube flanging by extrusion with a moving sleeve.

\section{DESCRIPTION OF THE INVESTIGATED PROCESS}

Two cases of extrusion with a moving sleeve are investigated. The tools used in both cases are the same, consisting of an upper punch 1 , a moving sleeve 3 and a lower punch 4 (Fig. 1a).

In Case 1 of the investigated extrusion process, shown in Fig. 1b, a billet in the form of a tube section is upset by the upper punch. When the material fills the cavity created between the upper punch, the lower punch and the sleeve, the sleeve begins to move opposite to the direction of the upper punch while the lower punch is maintained fixed.

In Case 2 (Fig. 1c), the workpiece is deformed by the action of the lower punch. Similarly to Case 1, once the material has filled the cavity created between the upper punch, the lower punch and the sleeve, the sleeve is set in motion, and its velocity vector has the same direction and sense as that of the lower punch. In Case 2, the upper punch is maintained fixed.

Due to the use of a moving sleeve in the extrusion process, the cavity volume increases as the process advances. This, in turn, prevents the workpiece from buckling and - at the same time - enables the formation of flanges of a considerable height.

\section{METHODS}

The study determined effects of the initial gap height $h_{0}$, flange diameter $D_{k}$ and tool motion on the analyzed extrusion process. 6 different flange diameters were tested. For every tested flange diameter, several different values of initial gap height were used. These values were selected such to determine the most favorable values of

a)

b)

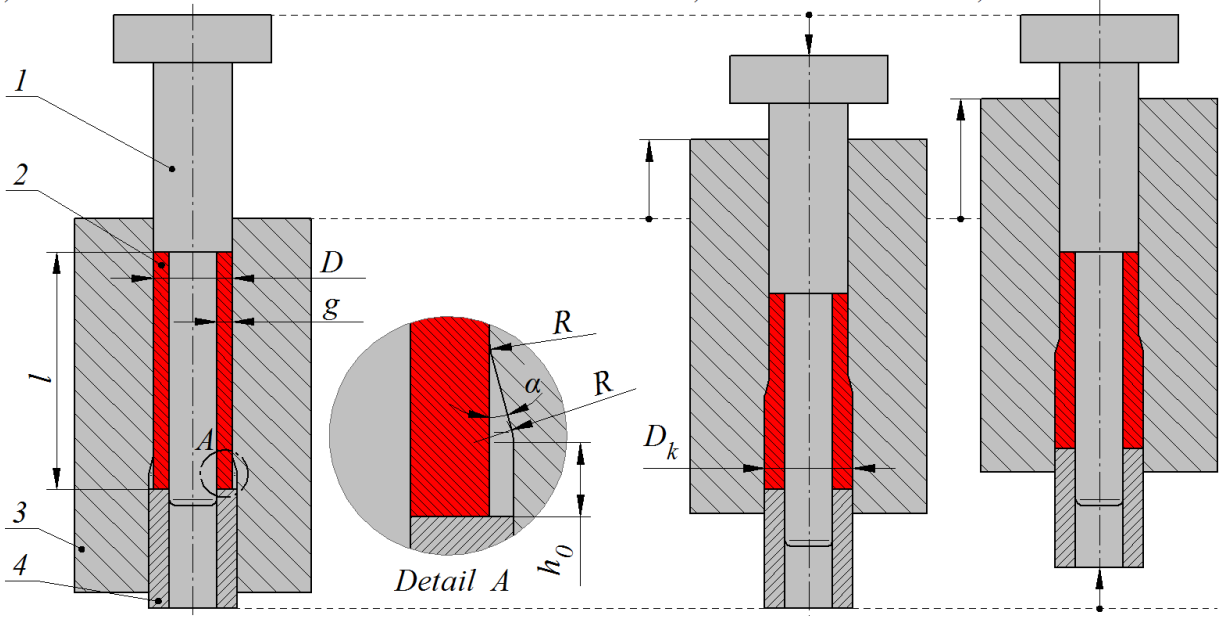

Fig. 1. Schematic design of extrusion with a moving sleeve: a) start of the process, b) end of the process

(Case 1), c) end of the process (Case 2); 1 - upper punch, 2 - workpiece, 3 - moving sleeve, 4 - lower punch 
Table 1. Parameters applied in the investigated cases of extrusion with a moving sleeve(denoted in accordance with Fig. 1 and Eqs.(1) and (2))

\begin{tabular}{|c|c|c|c|c|}
\hline \multirow{3}{*}{$\mathrm{D}_{\mathrm{k}},[\mathrm{mm}]$} & \multicolumn{4}{|c|}{ Parameters of the extrusion process } \\
\hline & \multicolumn{2}{|c|}{$\begin{array}{l}\text { Case } 1 \\
\text { (Fig.1b) }\end{array}$} & \multicolumn{2}{|c|}{$\begin{array}{c}\text { Case } 2 \\
\text { (Fig. 1c) }\end{array}$} \\
\hline & $\mathrm{h}_{0}[\mathrm{~mm}]$ & $v_{\mathrm{t} 1}[\mathrm{~mm} / \mathrm{s}]$ & $\mathrm{h}_{0}[\mathrm{~mm}]$ & $v_{\mathrm{t} 2}[\mathrm{~mm} / \mathrm{s}]$ \\
\hline 52 & $2 \div 36$ & 78.4 & $2 \div 36$ & 88.4 \\
\hline 54 & $2 \div 18$ & 38.4 & $2 \div 36$ & 48.4 \\
\hline 56 & $2 \div 10$ & 25.1 & $4 \div 36$ & 35.1 \\
\hline 58 & $2 \div 10$ & 18.5 & $6 \div 18$ & 28.5 \\
\hline 60 & $2 \div 10$ & 14.5 & $8 \div 18$ & 24.5 \\
\hline 62 & $2 \div 10$ & 11.9 & $10 \div 18$ & 21.9 \\
\hline \multicolumn{5}{|c|}{$\mathrm{D} \times \mathrm{g} \times \mathrm{I}=50 \times 10 \times 150[\mathrm{~mm}], \mathrm{R}=5 \mathrm{~mm}, \alpha=15^{\circ}$} \\
\hline
\end{tabular}

initial gap height for every tested flange diameter. The initial gap height values were selected based on an optimization research plan. In Case 2, the lower value of initial gap height was selected such to ensure that the volume of the material being deformed in the early stage of the process was not smaller than the cavity volume described with the initial gap height $h_{0}$. Details of the investigated extrusion cases are given in Table 1.

The extrusion process was modelled under the axisymmetric state of stresses using DEFORM. The study was performed on tubes (their dimensions are given in Table 1) made of $42 \mathrm{CrMo} 4$ steel, the material model of which was obtained from the material database library of the simulation software. Friction between the workpiece and the rigid tools was described with the constant friction model and the friction factor of $m=0.15$. The coefficient of heat transfer between the workpiece and the tools was set equal to $10 \mathrm{~kW} / \mathrm{m}^{2} \mathrm{~K}$. The upper and lower punch velocities were set equal to $10 \mathrm{~mm} / \mathrm{s}$, while the velocity of the moving sleeve was calculated based on Eqs. (1) and (2) for Case 1 and Case 2, respectively. The initial temperature of both the tools and the billet was set equal to $20^{\circ} \mathrm{C}$.

$$
\begin{gathered}
v_{t 1}=v_{s g} \cdot \frac{4 g(D-g)}{D_{k}^{2}-D^{2}}, \\
v_{t 2}=v_{s d} \cdot \frac{4 g(D-g)}{D_{k}^{2}-D^{2}}+v_{s d},
\end{gathered}
$$

where: $v_{t 1}$-sleeve velocity in Case 1 ,

$v_{t 2}$-sleeve velocity in Case 2,

$v_{s g}$-upper punch velocity,

$v_{s d}$-lower punch velocity; other denotations are the same as in Figure 1.

\section{RESULTS AND DISCUSSION}

Two stages can be distinguished in the process of extrusion with a moving sleeve. In the first stage, the material fills the cavity created between the moving sleeve and the upper and lower punches; the other stage occurs when the sleeve is set in motion to increase the flange height. The results demonstrate that the initial stage of extrusion with the moving sleeve significantly depends on the applied flange diameter, initial gap height and tool motion. These parameters affect metal flow in this process. 7 material flow patterns were identified, as shown in Figure 2 . The schematic representation of material flow patterns also shows the workpiece-tool contact zones. The contact zone between the workpiece and the upper punch is marked in blue, the contact zone between the workpiece and the moving sleeve is marked in yellow, while the contact zone between the workpiece and the lower tool is marked in orange. Depending on the applied technological parameters of extrusion, one can observe the presence of underfill, resulting - among others - from limited mechanical strength of the punches. The underfill occurs in the hole of the finished part, on the flank of the flange, or both. Figs. 2a, b and d show underfill located in the hole of the finished part. The underfill may start on the end face of the flange (Fig. 2a) or there may occur additional contact zones between the workpiece and the lower punch (Figs. $2 b$ and d). The metal flow patterns in Figs. $2 \mathrm{c}$ and e show that there is no underfill in the product hole. However, it occurs on the flank of the flange, and, as in previous cases, it may start on the end face of the workpiece (Fig. 

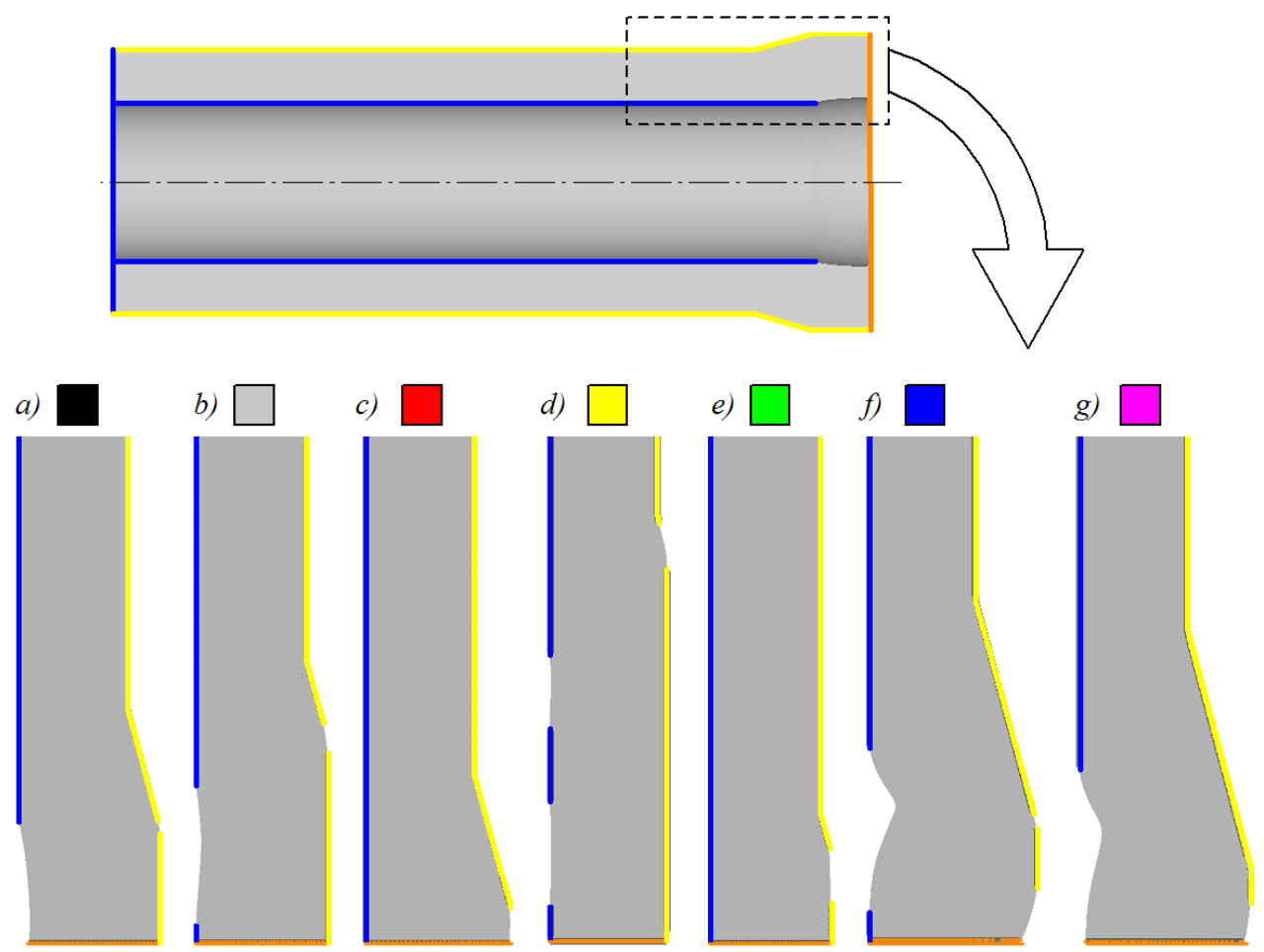

Fig. 2. Metal flow patterns (description in the text)

2c) or additional contact zones may be created between the workpiece and the moving sleeve (Fig. 2e). In Figs. 2f and g, underfill occurs both on the flange flank and in the hole of the finished part. Similarly to previous cases, underfill may start on the workpiece end face (Fig. 2g) or there may occur additional contact zones between the workpiece and the lower punch (Fig. 2f).

The above-mentioned metal flow patterns strictly depend on the extrusion process parameters such as flange diameter, initial gap height and tool motion, and the relationships between them are illustrated in Fig.3. An analysis of the data in this figure reveals that the application of higher values of initial gap height leads to underfill in the hole of the finished part. On the other hand, if the initial gap height is too low, underfill occurs on the flange flank. The results also demonstrate that with increasing the flange diameter, the flange forming process is disturbed, which causes underfill in the hole of the finished part and on the flange flank alike. What is more, the flange diameter increase observed in Case 2 makes it necessary to apply higher gap height values (to ensure that the cavity is filled with the required material volume at the early stage of extrusion), which - in turn - leads to underfill.

The metal flow pattern shown in Figure 2e seems to be the most desired, because it en- sures that -on starting the sleeve- the material will continue to fill the cavity and the flange height will keep increasing. As for other patterns, however, the underfill is of varying sizes. Measurements have shown that the highest radial underfill ranges from several micrometers to several millimeters. A slight underfill occurring at the early stage of extrusion has no negative effect on the extrusion process later on, when the sleeve is moving. Therefore, the metal flow patterns in which the highest radial underfill is below $0.1 \mathrm{~mm}$ are considered to be correct. A list of parameters ensuring correct realization of extrusion with a moving sleeve is given in Figure 4. The data demonstrate that - due to the limitations in the early stage of the investigated extrusion process - the maximum flange diameter $D_{k}$ is $54 \mathrm{~mm}$ and $56 \mathrm{~mm}$ in Case 1 and Case 2, respectively.

An analysis of the stage in which the sleeve is moving demonstrates that if the initial stage of the process proceeds correctly, then the following stage of the extrusion process is correct too. The results demonstrate that the tool movement direction is of vital importance in the second stage of the extrusion process and has a significant effect on the force parameters. Given the fact that the punches are under the highest load, Figs. 5 and 6 show examples of 


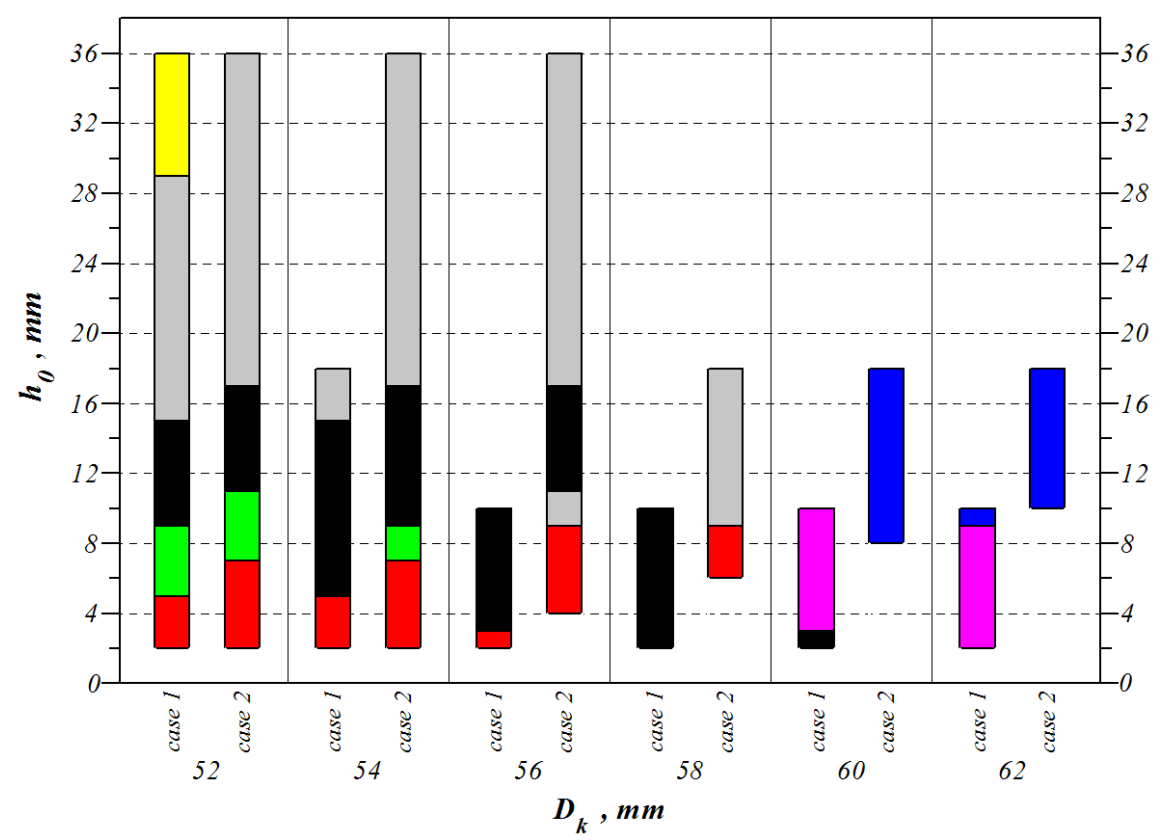

Fig. 3. Metal flow patterns in the tested cases of extrusion (denoted in acc. with Figs. 1 and 2)

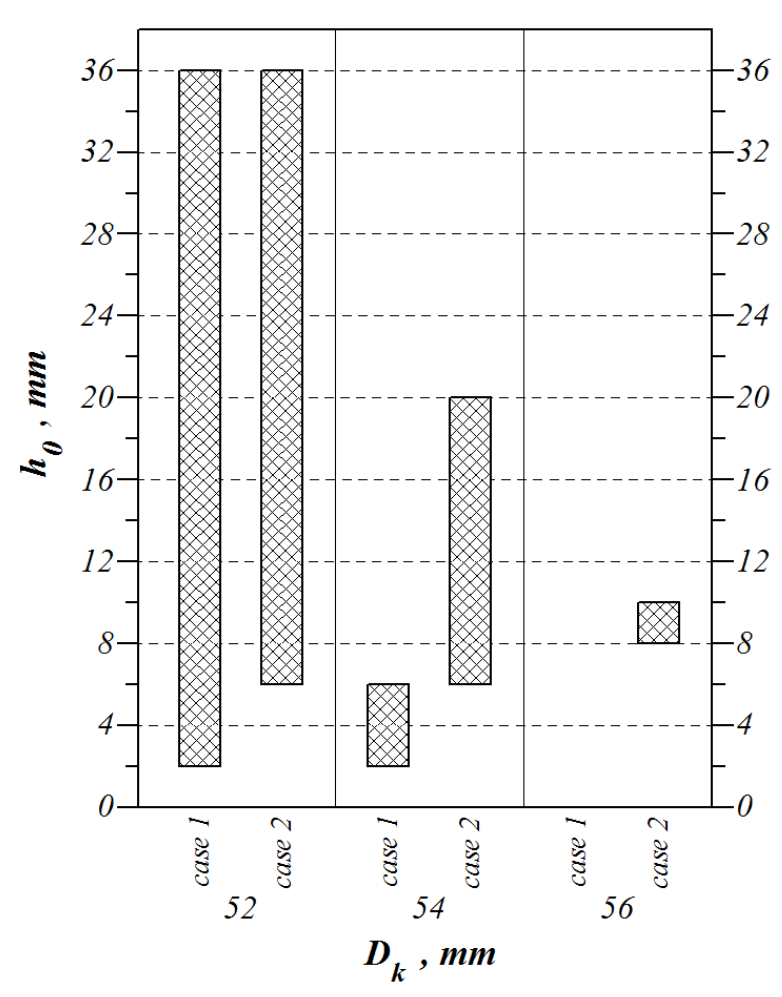

Fig. 4. List of parameters ensuring correct realization of extrusion with a moving sleeve

variations in the forces acting on these tools. The variations are similar in qualitative terms but differ in terms of quantity.

The force plots reveal that in Case 2 the forces applied to the upper and lower punch are approx. $5 \%$ lower than those in Case 1. This is due to the fact that in Case 1 the sleeve moves opposite to the punch, as a result of which the friction force between the sleeve and the workpiece leads to an increase in the force acting on the upper punch. In Case 2, however, the sleeve moves in the same direction as the lower punch. It should also be mentioned that the sleeve velocity is higher than the velocity of the lower punch (see Tab. 1). As a result, the friction force between the moving sleeve and the workpiece causes a decrease in the force acting on the lower punch, which results in active friction extrusion.

A qualitative analysis of the force variations reveals that the forces applied to the punches reach the highest values at the beginning of the extrusion process. Later on, they gradually begin to decrease. The force is the highest when the cavity described with the initial gap height $h_{0}$ is completely filled and the sleeve motion begins. The extrusion process reaches the steady state when the sleeve is in motion. Still, the force value does not remain constant but gradually decreases. This is caused by the friction forces occurring between the workpiece and the tools. In Case 1, the force applied to the upper punch decreases because the friction force decreases as the contact surface between the workpiece and the upper punch and sleeve is reduced. As a consequence, the force applied to the lower punch decreases too. In Case 2, the force applied to the lower punch decreases because the contact surface between the workpiece and the moving sleeve increases in the cavity zone in which the 


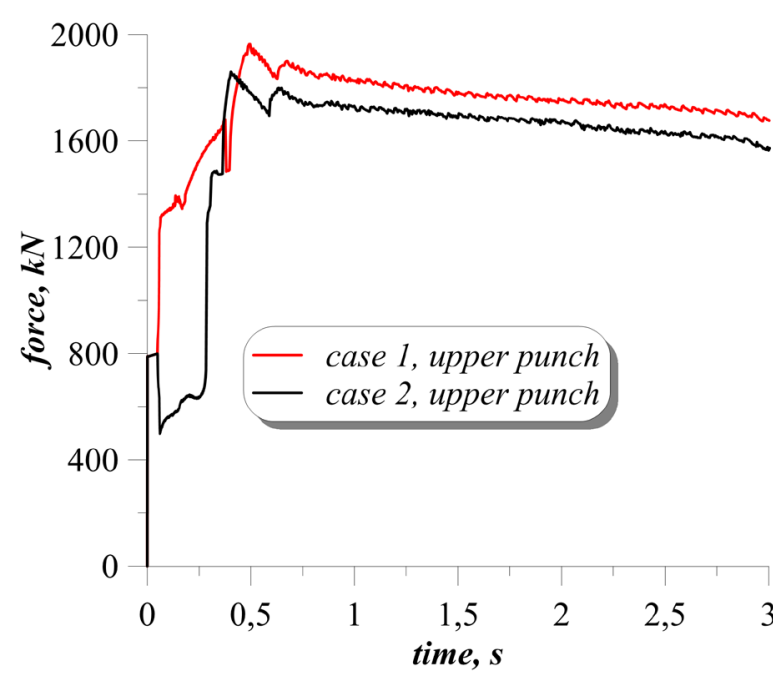

Fig. 5. Variations in the force applied to the upper punch; $\mathrm{D}_{\mathrm{k}}=54 \mathrm{~mm}, \mathrm{~h}_{0}=6 \mathrm{~mm}$

$D_{k}$ diameter flange is formed. As a result, the process-supporting active friction force increases. What is more, the unfavorable friction force between the workpiece and the upper punch decreases, which leads to a decrease in the force acting on the upper punch. The above-mentioned decrease in the force acting on the upper punch also results from a gradual decrease in the workpiece-sleeve contact surface in the cavity zone described with the diameter $D$.

\section{CONCLUSIONS}

The results of this study lead to the following conclusions:

1. The process of extrusion with a moving sleeve significantly depends on the initial gap height, flange diameter and tool motion (kinematics);

2 . The early stage of the process is of vital importance to the entire extrusion process - if this stage proceeds correctly, then the entire process is correct too;

3. Increasing the initial gap height and flange diameter at the early stage of the extrusion process leads to underfill;

4. Metal flow patterns depend on the tool motion;

5. Tool loading depends on the type of tool motion; in Case 2 (in which the workpiece is deformed by the lower punch) there occurs active friction, which leads to reduced loading of the tools in the extrusion process.

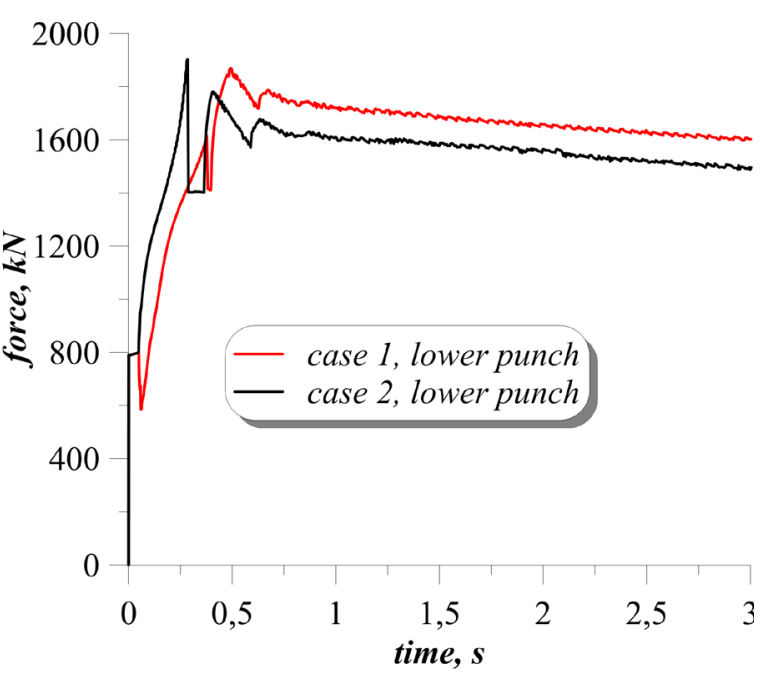

Fig. 6. Variations in the force applied to the lower punch; $\mathrm{D}_{\mathrm{k}}=54 \mathrm{~mm}, \mathrm{~h}_{0}=6 \mathrm{~mm}$

\section{Acknowledgement}

The research was financed in the framework of the project: New metal forming technique for producing flanged hollow parts for the mining industry, No. LIDER/1/0003/L-9/17/NCBR/2018. Total cost of the Project: 1197000 PLN. The project is financed by the National Centre for Research and Development under the 9th edition of the LIDER Programme.

\section{REFERENCES}

1. Hongchao J., Jinping L., Baoyu W., Xiaobin F., Wenchao X. and Zhenghuan H. A new method for manufacturing hollow valves via cross wedge rolling and forging: Numerical analysis and experiment validation. Journal of Materials Processing Technology, 240, 2017, 1-11.

2. Pater Z., Tomczak J. and Bulzak T. Analysis of a cross wedge rolling process for producing drive shafts. The International Journal of Advanced Manufacturing Technology, 94(9-12), 2018, 3075-3083.

3. Pater Z., Tomczak J. and Bulzak T. Cavity formation in cross-wedge rolling processes. Journal of Iron and Steel Research International, 26(1), 2019, 1-10.

4. Wang Z., Lu J. and Wang Z.R. Numerical and experimental research of the cold upsetting-extruding of tube flanges. Journal of Materials Processing Technology, 110(1), 2001, 28-35.

5. Hu X.L. and Wang Z.R. Numerical simulation and experimental study on the multi-step upsetting of a thick and wide flange on the end of a pipe. Journal of Materials Processing Technology, 151(1), 2004, 321-327. 
6. Samołyk G. Studies on stress and strain state in cold orbital forging a AlMgSi alloy flange pin. Archives of Metallurgy and Materials, 58(4), 2013, 1183-1189.

7. Samołyk G., Tomczak J. and Bartnicki J. Cold forming of $\mathrm{AlCu} 4 \mathrm{MgSi}$ alloy by orbital forging. Archives of Metallurgy and Materials, 57(1), 2012, 205-209.

8. Chan-hee N., Min-cheol L., Jae-geun E., Moo-ho C. and Man-soo J. Finite element analysis model of rotary forging for assembling wheel hub bearing assembly. Procedia Engineering, 81, 2014, 2475-2480.

9. Almeida B.P.P., Alves M.L., Rosa P.A.R., Brito A.G. and Martins P.A.F. Expansion and reduction of thin-walled tubes using a die: Experimental and theoretical investigation. International Journal of Machine Tools \& Manufacture, 46(12-13), 2006, 1643-1652.

10. Alves M.L., Almeida B.P.P., Rosa P.A.R. and Martins P.A.F.. End forming of thin-walled tubes. Journal of Materials Processing Technology, 177(1-3), 2006, 183-187.

11. Tomczak J., Bulzak T. and Pater Z. A method for producing hollow shafts by rotary compression using a specially designed forging machine. Archives of Metallurgy and Materials, 60(3), 2015, 1745-1753.

12. Tomczak J., Pater Z. and Bulzak T. Forming of hollow shaft forging from titanium alloy Ti6Al4V by means of rotary compression. Archives of Metallurgy and Materials, 60(1), 2015, 419-425.

13. Rosa P. A., Rodrigues J. M.C. and Martins P. A.F. Internal inversion of thin-walled tubes using a die: experimental and theoretical investigation. International Journal of Machine Tools \& Manufacture, 44(7-8), 2004, 775-784.
14. Qiu X. M., He L. H. and Yu X. H. An improved theoretical model of a metal tube under free external inversion. Thin-Walled Structures, 80, 2014, 32-37.

15. Gontarz A., Pater Z., Tomczak J. and Winiarski G. Theoretical and experimental research on a method for producing a triangular rosette-shaped flange. Key Engineering Materials, 622-623, 2014, 1166-1172.

16. Zhang X., Cheng G. and Zhang H. Numerical investigations on a new type of energy-absorbing structure based on free inversion of tubes. International Journal of Mechanical Sciences, 51(1), 2009, 64-76.

17. Umesh C. P., Susanta K. S., Pusparaj D. and Kanhu C. N. Simulation and experimental studies for lateral extrusion of square and pentagonal head from round shaft. International Journal of Research in Engineering and Technology, 2(7), 2013, 56-62.

18. Payman A. and Igramotdin A. Finite element simulation of flashless radial extrusion process. Journal of Mechanical and Civil Engineering, 14(4), 2017, 79-83.

19. Winiarski G., Gontarz A. and Dziubińska A. The influence of tool geometry on the course of flanges radial extrusion in hollow parts. Archives of Civil and Mechanical Engineering, 17(4), 2017, 986-996.

20. Winiarski G., Gontarz A. and Samolyk G. Flange formation in aluminium alloy EN AW 6060 tubes by radial extrusion with the use of a limit ring. Archives of Civil and Mechanical Engineering, 19(4), 2019, 1020-1028.

21. Winiarski G. and Gontarz A. Numerical and experimental study of producing two-step flanges by extrusion with a movable sleeve. Archives of Metallurgy and Materials, 62(2), 2017, 495-499.

22. Gontarz A. and Winiarski G. Numerical and experimental study of producing flanges on hollow parts by extrusion with a movable sleeve. Archives of Metallurgy and Materials, 60(3), 2015, 1917-1921.
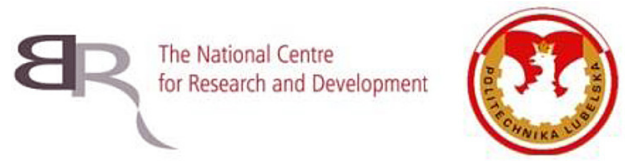

L I DER 